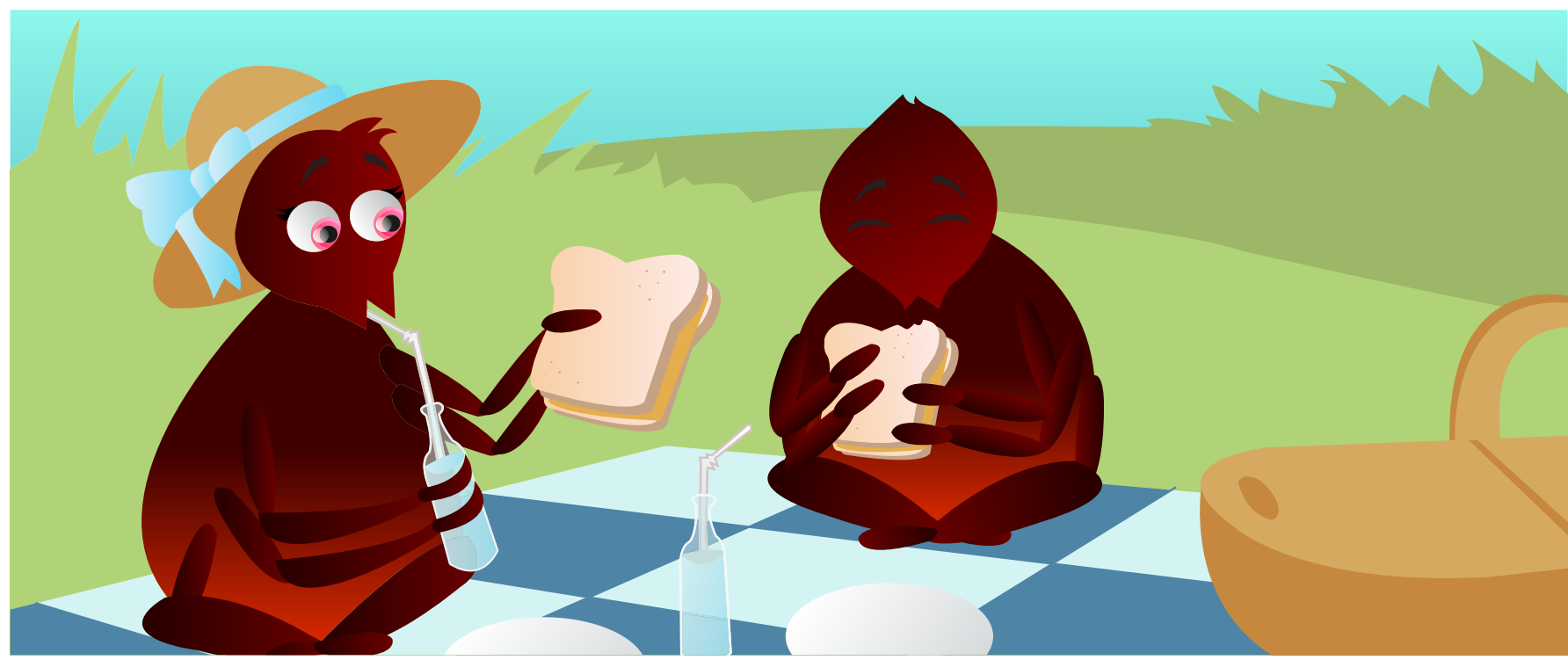

\title{
BE AWARE OF TICKS WHEN STROLLING THROUGH THE PARK
}

\section{Alejandro Cabezas-Cruz ${ }^{1 *}$, Agustín Estrada-Peña ${ }^{2}$, James J. Valdés ${ }^{3,4}$ and José de la Fuente ${ }^{5,6}$ \\ ${ }^{1}$ Center for Infection and Immunity of Lille (CIIL), INSERM U1019 - CNRS UMR 8204, Institut Pasteur de Lille, Université Lille Nord

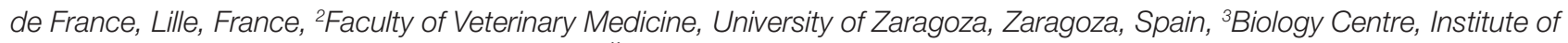 Parasitology, The Czech Academy of Sciences, České Budějovice, Czech Republic, ${ }^{4}$ Department of Virology, Veterinary Research Institute, Brno, Czech Republic, 5 SaBio, Instituto de Investigación en Recursos Cinegéticos IREC-CSIC-UCLM-JCCM, Ciudad Real, Spain, ${ }^{6}$ Department of Veterinary Pathobiology, Center for Veterinary Health Sciences, Oklahoma State University, Stillwater, OK, USA}

\section{REVIEWED BY:}

JACK

14 YEARS OLD

\section{CAPITULUM}

Mouthpart of ticks that includes the hypostome, two chelicera, and two palps.
Ticks are a type of organism found all over the world that feeds on blood. Ticks feed on many different animal hosts, including humans. Tick bites are usually not noticed by the host because tick saliva contains molecules that prevent inflammation (swelling) and pain. By remaining unnoticed by the host, ticks can often feed for several days without interruption. This causes a major problem since ticks can transmit disease-causing organisms while blood-feeding. This article provides information on how ticks evolved, their anatomy, life cycle, the diseases they transmit, and lastly, how to prevent tick bites.

\section{TYPES OF TICKS}

There are about 800 different kinds (species) of ticks, and they can be divided into three main families, called Ixodidae, Argasidae, and Nuttalliellidae. Ixodidae are also called hard ticks, and the structure they use for blood feeding (the capitulum) is visible. Argasidae are called soft ticks, and the capitulum 
PHYLOGENY

A diagram showing the history of the development of something. In biology, phylogeny often refers to a diagram describing the evolutionary history of proteins or organisms.

\section{CLADOGRAM}

Graphic representation of a phylogeny.

\section{EPIDEMIOLOGY}

The study of how disease spreads and how it can be controlled.

\section{FIGURE 1}

Main structural difference between hard $\mathbf{A}$. and soft $\mathbf{B}$. ticks. The figure displays the view of the back of the ticks. The main difference between hard and soft ticks is the visibility of the capitulum, which is visible in hard ticks and not visible in soft ticks. is not visible. The major difference between soft and hard ticks is shown in Figure 1. Nuttalliellidae is considered as the evolutionary link between soft and hard ticks. This article focuses on hard ticks because they are the ticks that spread the most diseases to humans worldwide. We made up a name for all 650 species of hard ticks: Ixodes solitarius. We will use this name throughout the paper to make it easy to refer to all hard ticks but remember that there are no actual tick species with this name.

\section{TICKS ARE COUSINS OF MOSQUITOES AND SISTERS OF SPIDERS AND SCORPIONS}

Ixodes solitarius appeared on earth about 250 million years ago (MYA) [1]. It is very difficult to imagine how the ancestors of $I$. solitarius were. Since we cannot travel in time, scientists use a type of computer-based analysis known as phylogeny. Phylogeny is a method that shows how species that are alive now are related to species that existed in the past by analyzing the similarities and differences in their genes (DNA) or body characteristics. The cladogram in Figure 2 shows that mosquitoes, ticks, spiders, and scorpions had a single common ancestor around 700 MYA [2]. The body structure of ticks indicates that they are more closely related to spiders and scorpions than to mosquitoes. An easy way to remember this relationship is that adult ticks, spiders, and scorpions have eight legs, while mosquitoes only have six. However, it is important to note that $I$. solitarius have eight legs only when they are young or as adults, but when they first hatch from the egg, they only have six legs, like mosquitoes.

\section{TICKS AND THEIR ENVIRONMENT}

The way ticks develop and interact with their environment is complicated, but it is important to understand how ticks develop and search for hosts. Any information about how ticks live is the basis for understanding the epidemiology of tick-borne diseases, meaning how these diseases spread and how we can control them. Since ticks are blood feeders, they must ingest large amounts of blood to completely develop. An adult female I. solitarius

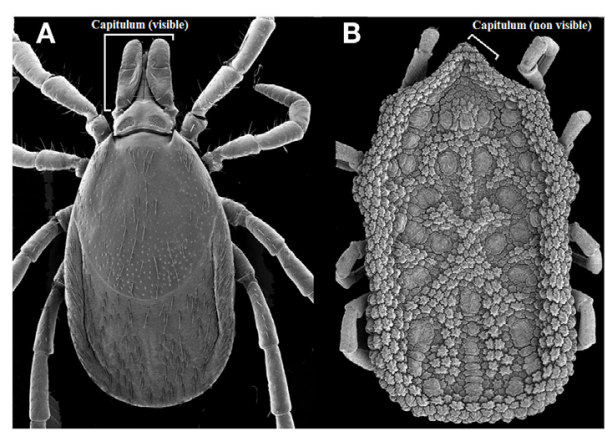

FIGURE 1 


\section{FIGURE 2}

The figure displays a cladogram with our current view on the relation between ticks, mosquitoes, spiders, and scorpions. The horizontal and vertical lines represent the evolutionary connections between these organisms, which shared a common ancestor in the past, 700 MYA. The relation between these groups was taken from Jeyaprakash and Hoy [1]

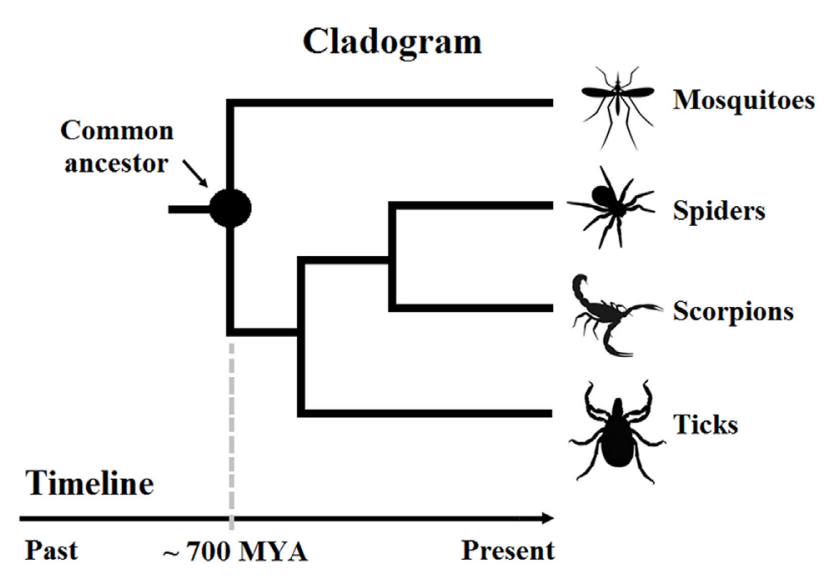

FIGURE 2

may ingest as much as 5-10 times their weight in blood in one feeding. After the female feeds on a host and mates, she drops to the ground and finds shelter in leaves or other natural material to lay thousands of eggs. Temperature controls egg development. The higher the temperature, the faster the eggs develop. There is an optimal temperature that varies among tick species, but $20^{\circ} \mathrm{C}$ is a good average temperature for egg development. Temperatures higher than $20^{\circ} \mathrm{C}$ increase the chance that the eggs will die. The immature tick that hatches out of the egg is called a larva. The larvae must then find a host. [Note: a tick's life cycle has three developmental stages after it hatches from the egg, the larva, the nymph, and the adult (male or female). You can see the tick developmental cycle in the video accompanying the recent publication by Kocan and coauthors [3].]

Ticks are not insects and cannot fly. They can only move long distances while feeding on a host, as the host moves around its environment. The smaller larvae and nymphs prefer to feed on small hosts such as rodents, birds, or lizards. Adult ticks need to ingest larger amounts of blood; therefore, they prefer to feed on large animals such as cattle, deer, horses, or humans. To find a host, I. solitarius climbs up onto vegetation, such as grass. This behavior is regulated by the weather. When the tick is on the vegetation waiting for a host, it is exposed to the sun and wind and loses water quickly. To rehydrate, the tick must go down to the ground again. If the humidity (amount of water in the air) is high, the tick may remain on the vegetation, waiting for a host, for longer periods of time.

Ticks are usually not picky about their hosts, so, while waiting on the vegetation, ticks attach to any suitable host that passes by. This is why humans are at risk when walking in the forest, or in the garden, without protection such as long socks or trousers. Once on the host, the tick will find a good place to feed and will insert its mouthparts to begin ingesting blood. The mouthparts of ticks include three main components known as hypostome, chelicera, and palps (Figure 3). While the hypostome and chelicera are completely inserted 


\section{FIGURE 3}

When feeding, ticks completely introduce the hypostome and chelicera in the skin. However, the palps remain outside of the feeding lesion.

\section{KUNITZ PEPTIDE}

Small proteins (less than 60 amino acids) that usually inhibit degrading enzymes known as proteases.

\section{LIPOCALIN}

A protein family involved in transporting small, organic molecules.

\section{HISTAMINE}

An organic molecule naturally occurring in animals, usually involved in inflammation.

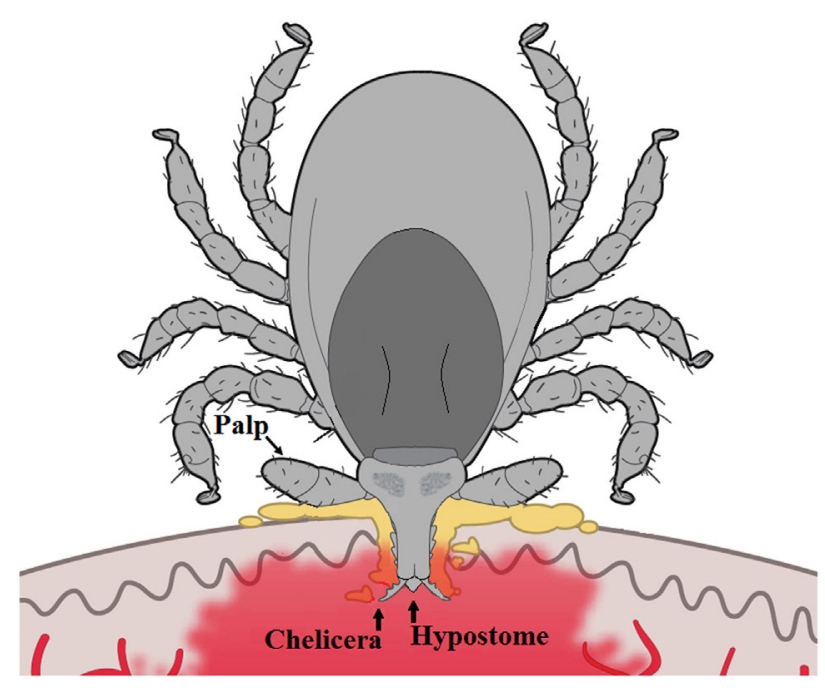

FIGURE 3

in the skin of the host, the palps remain outside. The feeding process may take 3-4 days for the small larvae and nymphs and up to 10 days for the large females.

\section{TICK SALIVA AS CAMOUFLAGE}

Tick saliva is secreted by the salivary glands through the mouthparts. Substances in the tick's saliva help the tick to fight off the normal responses of the host, such as blood clotting and inflammation. One tick salivary substance that interferes with blood clotting is called Kunitz peptide. Kunitz peptides are small molecules that are also secreted by venomous organisms, such as scorpions and spiders, and they are an important component of tick saliva [4]. Tick salivary Kunitz peptides interfere with blood clotting, allowing the tick to slurp up its blood meal.

Lipocalin is another tick salivary substance that interferes with inflammation. Have you ever been bitten by a mosquito? Does it hurt and leave a bump on the skin? Whenever you are cut, pricked, or bitten, your body usually responds by producing a substance called histamine, which causes inflammation. One tactic ticks use during blood feeding to prevent a host inflammatory response is to secrete lipocalins, which blocks the host's histamine. So, a tick bite does not cause a painful, itchy bump like a mosquito bite does.

It is interesting to mention that these properties of tick saliva might be useful for medical purposes. Since Kunitz peptides interfere with blood clotting, they could be used, for example, in open heart surgery, when the doctors want to prevent blood clots from forming in the patient. Unwanted inflammatory responses include allergies and asthma; therefore, tick lipocalins that block histamine may be useful in treating these conditions. 


\section{PATHOGENS}

Microorganisms that produce harm to humans and/or animals.

\section{GENOME}

The entire DNA sequence of an organism that is found in the nucleus of the cells.

\section{WHEN TICKS BITE, THEY TRANSMIT INFECTIOUS DISEASES}

While feeding, I. solitarius can transmit different disease-causing organisms, called pathogens. These pathogens are mainly bacteria and viruses but can also be larger organisms called protozoa and helminths. Most tick-borne pathogens are transmitted in tick saliva. One exception is an organism called Hepatozoon canis, which is transmitted when an animal eats an infected tick. Diseases transmitted to humans by tick bites include Lyme disease, human granulocytic anaplasmosis, and tick-borne encephalitis. Lyme disease, caused by the bacterium Borrelia burgdorferi, is becoming more common, for example, about 300,000 Americans each year are infected with this disease. Typical symptoms of Lyme disease include fever, headache, fatigue, and a "bull's eye"-shaped skin rash. However, if untreated, Lyme disease can produce more severe symptoms and complications that include arthritis, neurologic symptoms, and heart problems. Human granulocytic anaplasmosis is caused by the bacteria Anaplasma phagocytophilum. The first symptoms of human granulocytic anaplasmosis typically begin within 1-2 weeks after the bite of an infected tick, and they include fever, headache, muscle pain, chills, nausea, abdominal pain, cough, and confusion. Finally, tick-borne encephalitis is caused by a virus, which directly attacks the brain and/or brain membranes (meninges). This is a common tick-borne disease in Europe, and at the beginning of the disease, the symptoms are non-specific and can be mistaken with the symptoms of other common diseases producing fever, headache, or vomiting. Later, as the disease progresses and the virus invades the brain, more specific symptoms appear including confusion, stiff neck, sensory disturbances, and/or paralysis.

Although we still do not understand everything about how ticks interact with their hosts and their pathogens [5], advances in this field will be aided by the fact that the genome (the entire DNA sequence of an organism that is found in the nucleus of the cell) for one type of tick has been sequenced, or decoded. This tick is Ixodes scapularis, an important tick for transmitting both Lyme disease and human granulocytic anaplasmosis [6].

\section{HOW TO AVOID TICK BITES}

The best way to avoid tick bites is to stay away from ticks. Examples of how to avoid ticks can be found at the website of the Centers for Disease Control and Prevention (CDC). ${ }^{1}$ About $80 \%$ of tick bites are reported between May and September, when ticks are very active. Therefore, more care should be taken when walking in woody and bushy areas during this period. Usually, strolling through the woods is more pleasurable during this period, so stay on the

${ }^{1}$ http://www.cdc.gov/ticks/avoid/on_people.html 
path and walk in the center of the trails. Spraying insect repellents on clothes and exposed skin when going for walks in risky areas is also recommended. Repellents that contain substances called DEET ( $N, N$-diethyl-m-toluamide) or permethrin will work to repel ticks. After any trip from woody and bushy areas, check your body closely in front of a mirror. I. solitarius nymphs can usually be found on the legs and arms, while adult ticks are found on the back, neck, head, groin, and genitals [7].

\section{ACKNOWLEDGMENTS}

AC-C was supported by the Ministère de l'Education Supérieure et de la Recherche and the Institut Pasteur de Lille. JV was supported by the CZ.1.07/2.3.00/30.0032 project, co-financed by the European Social Fund and the state budget of the Czech Republic, and project LO1218, with financial support from the MEYS of the Czech Republic under the NPU I program.

\section{REFERENCES}

1. Jeyaprakash, A., and Hoy, M. A. 2009. First divergence time estimate of spiders, scorpions, mites and ticks (subphylum: Chelicerata) inferred from mitochondrial phylogeny. Exp. Appl. Acarol. 47(1):1-18. doi:10.1007/s10493-008-9203-5

2. Sanders, K. L., and Lee, M. S. Y. 2010. Arthropod molecular divergence times and the Cambrian origin of pentastomids. Syst. Biodivers. 8(1):63-74. doi:10.1080/14772000903562012

3. Kocan, K. M., de la Fuente, J., and Coburn, L. A. 2015. Insights into the development of Ixodes scapularis: a resource for research on a medically important tick species. Parasit. Vectors 8:592. doi:10.1186/s13071-015-1185-7

4. Cabezas-Cruz, A., and Valdés, J. J. 2014. Are ticks venomous animals? Front. Zool. 11:47. doi:10.1186/1742-9994-11-47

5. de la Fuente, J., Villar, M., Cabezas-Cruz, A., Estrada-Peña, A., Ayllón, N., and Alberdi, P. 2016. Tick-host-pathogen interactions: conflict and cooperation. PLoS Pathog. 12(4):e1005488. doi:10.1371/journal.ppat.1005488

6. Gulia-Nuss, M., Nuss, A. B., Meyer, J. M., Sonenshine, D. E., Roe, R. M., Waterhouse, R. M., et al. 2016. Genomic insights into the Ixodes scapularis tick vector of Lyme disease. Nat. Commun. 7:10507. doi:10.1038/ncomms10507

7. Wilhelmsson, P., Lindblom, P., Fryland, L., Nyman, D., Jaenson, T. G., Forsberg, P., et al. 2013. Ixodes ricinus ticks removed from humans in Northern Europe: seasonal pattern of infestation, attachment sites and duration of feeding. Parasit. Vectors 6:362. doi:10.1186/1756-3305-6-362

SUBMITTED: 16 May 2016; ACCEPTED: 20 September 2016;

PUBLISHED ONLINE: 06 October 2016.

EDITED BY: Caroline Helen Brennan, Queen Mary University of London, UK 
CITATION: Cabezas-Cruz A, Estrada-Peña A, Valdés JJ and de la Fuente J (2016) Be Aware of Ticks When Strolling through the Park. Front. Young Minds 4:24. doi:10.3389/ frym.2016.00024

CONFLICT OF INTEREST STATEMENT: The authors declare that the research was conducted in the absence of any commercial or financial relationships that could be construed as a potential conflict of interest.

COPYRIGHT (C) 2016 Cabezas-Cruz, Estrada-Peña, Valdés and de la Fuente. This is an open-access article distributed under the terms of the Creative Commons Attribution License (CC BY). The use, distribution and reproduction in other forums is permitted, provided the original author(s) or licensor are credited and that the original publication in this journal is cited, in accordance with accepted academic practice. No use, distribution or reproduction is permitted which does not comply with these terms.

\section{REVIEWED BY}

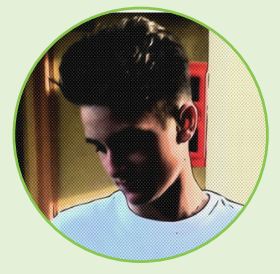

\section{JACK, 14 YEARS OLD}

I am a huge soccer fan and Pokemon enthusiast, hoping for a career in health-care engineering!

\section{AUTHORS}

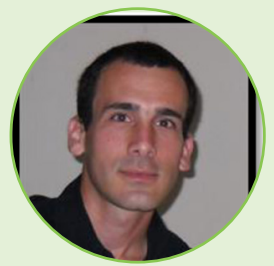

\section{ALEJANDRO CABEZAS-CRUZ}

I am a highly enthusiastic parasitologist, very interested in the biology of ticks and tick-borne pathogens. I have a Doctor of Veterinary Medicine Degree from the University of Havana and two PhDs, one in Tick Biology that I defended on October 2014 in Spain and the other in Parasite Epigenetics that I defended on September 2016 in France. Particularly, I want to understand the evolution of tick and tick-borne pathogen associations.

*cabezasalejandrocruz@gmail.com

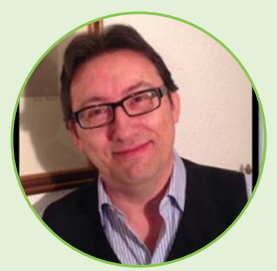

\section{AGUSTIN ESTRADA-PEÑA}

I am a Professor of Zoonoses and Parasitology in the Faculty of Veterinary Medicine at Zaragoza (Spain). My main field of work is to understand how ticks and tick-borne pathogens spread in nature. For this aim, I use information from satellites, meta-analysis of the prevalence of the pathogens in the field, and modeling of tick systems. I also contribute as consultant of international health organizations for topics concerning tick-transmitted pathogens.

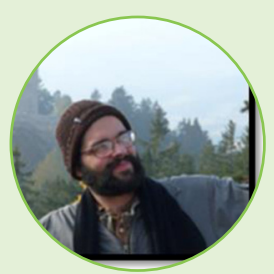

\section{JAMES J. VALDÉS}

I studied psychology and neuroscience at Florida International University (USA) and received my PhD in Biology (2009). I am currently a research scientist in the Czech Republic investigating tick salivary molecules. My research aim is to investigate how these molecules behave at the atomic level, a field of science known as biophysics. I am also a lecturer in computational biology and biochemistry at the Faculty of Science, University of South Bohemia (Czech Republic). 


\section{JOSÉ DE LA FUENTE}

I am a Professor at the Spanish Research Council (CSIC) and the University of Castilla-La Mancha, Spain \& Adjunct Professor at Veterinary Pathobiology, Oklahoma State University, USA. My current research interests are infectious diseases, systems biology of host-vectorpathogen interactions, ticks and tick-borne diseases, vaccinology, and biotechnology. 